American Journal of Pharmaceutical Education 2019; 83 (4) Article 7593.

\title{
COMMENTARY
}

\section{It Really Isn't That Simple}

\author{
Lucinda L. Maine, $\mathrm{PhD}, \mathrm{RPh}$ \\ Executive Vice President and CEO, American Association of Colleges of Pharmacy, Arlington, Virginia \\ Submitted April 8, 2019; accepted April 8, 2019; published May 2019.
}

In early February of this year, a petition was initiated by several pharmacists on change.org. "Halt New PharmD Accreditation to 2030 " was signed by almost 10,000 additional petitioners in just a week. The fundamental premise is that the job market for pharmacists can no longer accommodate the number of PharmD graduates. They specifically asked the American Association of Colleges of Pharmacy, the Accreditation Council for Pharmacy Education, and the American Pharmacists Association to take action to prevent the opening of more new schools. The three organizations worked to prepare and disseminate a joint response which was posted to the petition site shortly after the petition was started and is available on each organization's website. ${ }^{1}$

Following the posting of the joint response, petitioners modified their appeal for action by national pharmacy organizations. Petitioners clearly seek relief from current working conditions and express the sentiment that the supply of pharmacists in some parts of the country outstrips demand. This has been true for several years in those areas where multiple schools of pharmacy are located in the same city. It is true that many graduates have a preference to stay, if possible, where they have established friends and may also have family members.

The petition raises many questions, but this commentary is framed around one question specifically: Is what is happening in parts of the profession really as simple as too many new schools and too many graduates? As I pondered this question, not for the first time, I realized that a longitudinal analysis of pharmacist workforce dynamics over the last two decades might be a contribution that would serve the entire profession. This commentary is intended to complement the paper by Lebovitz and Eddington published in the Journal earlier this year. ${ }^{2}$

Just about 20 years ago the raging question was "Is there truly a shortage of pharmacists?" Employers of pharmacists insisted that there was. On the flip side, others simply asked if there were too many new stores opening. One chain proudly declared that they were opening new

Corresponding Author: Lucinda L. Maine, American Association of Colleges of Pharmacy, 1400 Crystal Dr., Ste. 300, Arlington, VA 22202. Tel: 703-739-2330. E-mail: lmaine@aacp.org stores at a rate of one every 17 hours! A request was made through the legislative branch for the Health Resources and Services Administration (HRSA) in the Department of Health and Human Services to assess the pharmacy workforce and identify factors that might influence the balance between the demand for and supply of licensed pharmacists.

Colleges and schools of pharmacy at that time were in the final stages of preparing to phase out those bachelor's degree programs that were still graduating pharmacists, including some of the schools with the largest class sizes. Only a handful of new schools had opened in the 1980s and 1990s. When making a transition to the PharmD, some schools decreased their class size, spreading the same number of learners over the four-year curriculum as they had enrolled in the three final years of the B.S. program. The graduation cohort dipped to just over 7,000 in $1999 .^{3}$

\section{There Was a National Pharmacist Shortage}

In the year 2000, the report to Congress on the pharmacy workforce was released and received substantial attention both in and out of the profession. ${ }^{4}$ Workforce researchers from the University of Illinois in Chicago conducted the analysis under contract with HRSA, conducting interviews with many knowledgeable experts. The assessment confirmed that there was an imbalance of supply and demand that had created a national shortage of pharmacists and noted those factors contributing to the situation. Certainly, the decrease in the graduation cohort was one factor on the supply side. The demand for pharmacists was being fueled by several factors, including the aging of the population, increased incidence of chronic illness, a rapidly rising volume of prescriptions and medication orders and other factors. The analysts posited that the shortage likely would continue for some time. Indeed, the shortage did persist for most of that decade and salaries rose significantly across all settings where pharmacists were employed.

Mainstream public media outlets paid attention to the report to Congress and its conclusions regarding a pharmacist shortage. At this same time a great deal of attention 


\section{American Journal of Pharmaceutical Education 2019; 83 (4) Article 7593.}

to patient safety, including medication errors, had been stimulated by "To Err is Human" and "Crossing the Quality Chasm"6 released by the Institute of Medicine (now the National Academy of Medicine). Investigative reporters wanted to know if the pharmacist shortage was contributing to medication errors and patient harm. This provided the profession's spokespersons a unique opportunity for in-depth explanations of what pharmacists should be contributing to safe and effective patient care.

\section{Professionally Determined Need for Pharmacists}

In this same period, University of Maryland Dean David Knapp approached the Pharmacy Manpower Project (now Pharmacy Workforce Center) with a proposal for a project to try and estimate the future need for pharmacists in 2020. Knowing that there were no robust estimates that considered key issues like the magnitude of drug-related problems, aging of the population and other factors, the PMP board approved funding for a unique meeting of two dozen pharmacy practice experts. After three days of discussions and small group deliberations, estimates were made of the number of pharmacists needed for order fulfillment, primary patient care services, secondary/tertiary services and indirect or other pharmacist services. ${ }^{7}$ The project's estimates for the number of pharmacists required to meet societal needs in 2020 is reproduced in Table 1.

The following two conclusions came from the experts' deliberations: The health care of the public would be improved if the amount of high-quality pharmaceutical care services provided to patients was increased significantly, either by pharmacists or some other means; and, the total amount of such services needed over the next 20 years will exceed the supply of pharmacists, even if the maximum redeployment of pharmacists from order fulfillment functions to patient care is accomplished.

Table 1. Current and Projected Need for Pharmacists in the United States $^{7}$

\begin{tabular}{lcc}
\hline & $\begin{array}{c}\text { 2001 Use of } \\
\text { Pharmacists }\end{array}$ & $\begin{array}{c}\text { Projected Need } \\
\text { for Pharmacists } \\
\text { in 2020 }\end{array}$ \\
\hline Order fulfillment & 136,400 & 100,000 \\
Primary services & 30,000 & 165,000 \\
Secondary/tertiary services & 18,000 & 130,000 \\
Indirect/other services & 12,300 & 22,000 \\
Total & 196,700 & 417,000 \\
Total estimated supply & & 260,000 \\
Shortfall & & 157,000 \\
\hline
\end{tabular}

In addition to these statements, conferees concluded that to fully meet the anticipated need for pharmaceutical care "the profession of pharmacy should not only continue to emphasize improved utilization of its members, but also move rapidly to increase the overall size of its enterprise."

\section{Acceleration of the Establishment of New Schools and Branch Campuses}

The increased number of public media stories generated in the wake of patient safety concerns often cited that pharmacists were now paid in excess of $\$ 100,000$, not including bonuses for multi-year commitments to an employer. Graduates were receiving multiple offers of employment, typically early in their final year of education. The competition for available seats in colleges and schools of pharmacy across the country began to intensify.

AACP launched PharmCAS, the centralized application service for pharmacy programs, in 2004. PharmCAS made it much easier for an applicant to apply to multiple programs with a single application. The service also increased the ease and efficiency with which the admissions personnel at a school could handle the increasing number of applications they were receiving. As larger numbers of candidates were being denied admission, universities that did not already have a college or school of pharmacy began to analyze the process and business case for adding this major to their catalogs. In addition, to meet the need for additional pharmacy graduates, existing colleges and schools began opening branch campuses and satellite programs. Creighton University boldly implemented an online pathway to the PharmD, which made pharmacy careers feasible for learners geographically distant from traditional campus programs.

The pace of new school openings between 2001 and 2018 was dizzying, including the establishment of multiple satellite sites and branch campuses. The number of schools rose from 83 in 2002 to 142 in 2018 and the number of graduates in Spring of 2018 numbered slightly more than $14,500 .^{8}$ In 2017, the National Association of Boards of Pharmacy (NABP) reported that more than 325,000 pharmacists were licensed in the United States according to the e-profile aggregate data. ${ }^{9}$ As NABP does not collect information on how many FTEs this represents, the total workforce capacity can only be estimated.

\section{Underappreciated Consequences of the Pharmacist Shortage}

Various segments of the profession viewed the national pharmacist shortage through different lenses. Employers struggled to keep operations running when there 


\section{American Journal of Pharmaceutical Education 2019; 83 (4) Article 7593.}

was an insufficient number of licensed practitioners to serve every community and institutional practice across the country. While positions serving rural and underserved communities likely struggled the most, even in suburbs such as those around Washington, DC, there were days when some pharmacies posted store or at least pharmacy department closures due to lack of personnel. Rapidly rising salaries and the need to provide generous benefits even for part-time pharmacists also put pressure on the corporations and institutions employing pharmacists, including colleges and schools of pharmacy.

A rarely discussed consequence of the national shortage is the likely impact it had on the advancement of pharmacists' patient care services. This was a period when pharmacists were experiencing growing empowerment to provide immunizations, especially to the elderly. Some sectors of the profession were slow to adopt these practices, even when such services helped them realize new streams of revenue. Work to implement chronic care patient management services, including those well documented for improving patient outcomes, also lagged. Compensation for those services was not as accessible as for immunizations and this remains an issue of professional concern even today.

When the Medicare Prescription Drug Benefit passed in 2003, analysts predicted continuous increases in the total volume of prescriptions that would result when the last group of insured people, and the heaviest prescription utilizers, finally became eligible for medication coverage. Included in the benefit structure were medication therapy management services to be offered by the Medicare Part D plan sponsors. Even though such services when first implemented in 2006 were minimalist in most cases and not always provided by the patient's pharmacist, it appeared that the profession was finally making progress in its quest for recognition that our graduates are prepared to offer much more than prescription order fulfillment.

\section{The Recession}

The near collapse of the world economy late in the last decade played out in several different ways in pharmacy education and practice. Individuals with college degrees in fields badly hurt in the recession looked to other fields that seemed somewhat more recession proof. Returning to school to earn a PharmD in 3 or 4 additional years of study seemed reasonable when six-figure salaries and many open positions beckoned. The fact that both public and private university tuitions had risen markedly over the past several years did not deter many applicants. The number of applications to the growing number of colleges and schools continued to climb.
One trend that suffered in the recession was the pace of new pharmacy openings across the country. Large chains turned to acquisitions of existing smaller chains rather than building new stores. And pharmacists who were poised to retire, perhaps at an earlier age than the average worker, stayed in the workforce when retirement savings suffered. Individuals who had stepped out of practice or had been working part time returned or increased their hours to full time. If one's spouse were laid off in the recession, the pharmacist had little choice but to return to full-time employment with benefits. Yet despite these changes in the marketplace, new graduates still found positions relatively plentiful in the early years of the second decade of the $21^{\text {st }}$ century.

\section{Dramatic Changes in Health Care and Pharmacy}

Many forces have altered health care services and systems in the current decade and pharmacy felt many of these. Congress passed the Affordable Care Act (ACA) in 2010, expanding access to health insurance for millions previously uninsured. The ACA included a provision for the establishment of the Center for Medicare and Medicaid Innovation. With health care quality improvement guru Donald Berwick at the helm of CMS early in the Obama administration, the agency that covers more than $50 \%$ of the US population began to experiment with new models of payment and care delivery systems. "Paying for value" is the phrase that captures, and somewhat explains, new public and private sector payment strategies for health care services.

Hospitals and health systems responded with a dizzying amount of acquisition and network creation in anticipation of changes in both public and private sector coverage for prevention and treatment of acute and chronic illness. Value-based purchasing and quality metrics dominated the health care landscape. One example of a bold change in payment from CMS and some private insurers is the 30-day readmission regulation for several conditions (eg, congestive heart failure). If a patient is discharged with a target diagnosis and is readmitted within the first 30 days, the payer does not provide compensation for the readmission. Medication management can be extremely important in such cases and transitions of care programs have emerged.

Charles Dickens opened The Tale of Two Cities with the line "It was the best of times. It was the worst of times." For pharmacies and pharmacists, this line seems to capture the dynamics in the profession over the last 8 to 10 years. The demand for post-graduate residency (PGY) positions soared, outstripping the available PGY1 positions. That said, organizations have responded by increasing both PGY1 and 


\section{American Journal of Pharmaceutical Education 2019; 83 (4) Article 7593.}

PGY2 positions significantly over the past decade. Many pharmacist openings in health systems now require or at least express a strong preference for residency training of at least one year. Ambulatory care positions (the primary care pharmacists in the Knapp analysis) have increased quite dramatically as pharmacists demonstrated their value in medication management for chronic conditions and complex patients. The Board of Pharmacy Specialties began certifying ambulatory care pharmacy specialists in 2009 and the number has grown to almost 10,000 in the last decade. ${ }^{10}$

For the past several sessions of Congress, national pharmacy associations and employers have joined forces to work collaboratively to secure legislation modifying the Medicare program to finally recognize pharmacists among the other named providers eligible to participate in Medicare with reimbursement. Bipartisan co-sponsors introduced "provider status" legislation in both the House and the Senate. Alas, at the end of 2018 when the $115^{\text {th }}$ Session of Congress ended, the much-needed legislative change had still not made it to a vote in either the House or the Senate. The opportunity to, as APhA CEO Tom Menighan states repeatedly, "expand consumer access and coverage for pharmacists' quality patient care services" remains an elusive target. The minimal coverage of pharmacists' patient care services coupled with the steep and continuous decline in product-based reimbursement is causing significant pressure on community practice and affecting pharmacists' and technicians' hours and staffing.

\section{Changes in the Demand for Pharmacy Admission}

As the slow recovery from the recession progressed, colleges and universities began to experience changes in applications to both undergraduate and professional degree programs. Many families were stressed as they considered the cost of college tuition which had risen sharply over previous decades. Average student loan burden was also rising. At the same time, the demographics of the college rising population changed with low birth cohorts and a different ethnic mix of high school students and graduates. The fastest growing numbers of students were from demographic groups that sought college and professional degree programs in lower percentages than more traditional college entrants.

Pharmacy began to experience a flattening of the number of applicants around 2010 and over the last several years both the number of applicants and applications applying through PharmCAS decreased. Pharmacy is not alone in this experience as other health disciplines have seen a downtrend in applicants as well. Enrollment management has become an extremely challenging issue for some programs. Several universities have elected to close the branch campuses that provided relief during the previous shortage. First professional student enrollments in fall 2017 were down by $0.6 \%$ compared to fall 2016 .

The pace of new school openings slowed considerably over the past five years in comparison to the previous 5 -year period. Several programs that had announced the establishment of a PharmD program subsequently changed course.

\section{Too Many Pharmacists? Too Many Schools?}

Dr. John Gans, CEO of APhA from 1989 to 2009, liked to respond to the question of whether we had too many pharmacists with the quip "Too many pharmacists to do what?" Repeating the premise underlying the Knapp report: "the health care of the public would be improved if the amount of high-quality pharmaceutical care services provided to patients was increased significantly, either by pharmacists or some other means," it is painfully clear that the profession and others in health care have not yet made sufficient progress in the prevention and resolution of avoidable drug-related problems.

The profession has tested and studied various patient-care practice models. Some have been firmly established with pharmacists in in-patient, clinic and community settings demonstrating their unique value to patients and other health care team members. Pharmacists in the community setting have continued to increase the provision of a growing array of immunizations. State scope of practice changes empower many more pharmacists to offer point of care testing, treat common ailments, and initiate or modify patients' medication regimens under collaborative practice agreements and statewide protocols. Yet full implementation of such services lags both the regulatory empowerment and patient need.

In 2016, the AACP House of Delegates approved a new strategic plan for the Association. The top priorities aim to work in tandem to help the profession achieve its vision of patients realizing better health by optimizing the benefits of medications and pharmacists' services. It is to society's benefit to ensure that the right quality and quantity of students pursue pharmacy education such that the balance of supply and demand for pharmacists' services is achieved. To accomplish this, the public needs a more contemporary appreciation of what pharmacy graduates enter the workforce prepared to contribute to safe and effective patient care. Changes in both education and practice must accelerate to more effectively position pharmacists in a wide variety of settings to deliver on the promise of their education. Pharmacy educators and practitioners also need to address gaps in knowledge through research to 


\section{American Journal of Pharmaceutical Education 2019; 83 (4) Article 7593.}

ensure that new and old pharmaceutical products are available and used in the most effective manner to prevent and resolve medication-related problems.

Research shows that we have not yet achieved the aim of providing adequate medication management services in our current health care delivery models. Many forces, both positive and negative, contribute to our current reality. AACP and our member colleges and schools of pharmacy are committed to doing all we can to close the gaps to fully realize the promise of pharmacy education today and in the future.

\section{REFERENCES}

1. Response to changepharmacy.org petition. https://www.aacp. org/article/joint-response-petitioners-seeking-moratoriumaccreditation-new-pharmd-institutions. Accessed March 12, 2019.

2. Lebovitz L, Eddington ND. Trends in the pharmacist workforce and pharmacy education. Am J Pharm Educ. 2019; 83(1): Article 7051.
3. Meyer SM, Patton JM. The pharmacy student population: applications received 1998-99, degrees conferred 1998-99, fall 1999 enrollments. Am J Pharm Educ. 2000; 64, Winter Supplement.

4. Report to Congress on pharmacist shortage.

5. To err is human. Committee on Quality Health Care in America, Institute of Medicine; 1999.

6. Crossing the quality chasm: a new health system for the $21^{\text {st }}$ century. Committee on Quality Health Care in America, Institute of Medicine; 2001.

7. Knapp DA. Professionally determined need for pharmacy services in 2020. Am J Pharm Educ. 2002;66(4):421-429. http://archive.ajpe.org/ legacy/pdfs/aj660414.pdf.

8. Academic Pharmacy's Vital Statistics July 2018. https://

www.aacp.org/article/academic-pharmacys-vital-statistics. Accessed March 12, 2019.

9. American Association of Colleges of Pharmacy. 2014 NABP e-profile aggregate data report. https://www.aacp.org/sites/default/ files/2017_NABP_e-profile_aggregate_analysis_report.pdf. Accessed March 4, 2019.

10. Board of Pharmacy Specialties chart of certified specialists by year. https://www.bpsweb.org/wp-content/uploads/BPS-2019-

Growth-Chart.jpg. Accessed March 29, 2019. 